\title{
Distribution, Formation Mechanisms, and Significance of Lunar Pits
}

\author{
Robert V. Wagner, Mark S. Robinson \\ School of Earth and Space Exploration, Arizona State University, 1100 S. Cady Mall, Tempe, AZ 85287-3603
}

Published version at http://dx.doi.org/10.1016/j.icarus.2014.04.002

Corresponding author: Robert V.Wagner, rvwagner@asu.edu

Version date: 28 March 2014

(C) 2014. This manuscript version is made available under the CC-BY-NC-ND 4.0 license:

http://creativecommons.org/licenses/by-nc-nd/4.0/

\begin{abstract}
Lunar Reconnaissance Orbiter Camera images reveal the presence of steep-walled pits in mare basalt $(n=8)$, impact melt deposits $(n=221)$, and highland terrain $(n=2)$. Pits represent evidence of subsurface voids of unknown extents. By analogy with terrestrial counterparts, the voids associated with mare pits may extend for hundreds of meters to kilometers in length, thereby providing extensive potential habitats and access to subsurface geology. Because of their small sizes relative to the local equilibrium crater diameters, the mare pits are likely to be post-flow features rather than volcanic skylights. The impact melt pits are indirect evidence both of extensive subsurface movement of impact melt and of exploitable sublunarean voids. Due to the small sizes of pits (mare, highland, and impact melt) and the absolute ages of their host materials, it is likely that most pits formed as secondary features.
\end{abstract}

\section{Introduction}

Three $60 \mathrm{~m}$ to $100 \mathrm{~m}$ diameter mare pits were first identified in $10 \mathrm{~m}$ pixel scale SELENE images and were proposed to have formed as active lava tube collapses, sometimes known as skylights (Haruyama et al., 2009). Later $1 \mathrm{~m}$ pixel scale observations by the Lunar Reconnaissance Orbiter Camera (LROC) Narrow Angle Camera (NAC) (Robinson et al., 2010) revealed that at least two of these pits provide openings into subsurface voids of unknown lateral extent (Robinson et al., 2012). These discoveries led to an initiative to search for additional pits identifiable in meter-scale NAC images. This search revealed 228 previously unknown pits (Figure 1) with diameters ranging from $5 \mathrm{~m}$ to $900 \mathrm{~m}$, and a median pit diameter of $16 \mathrm{~m}$. The majority of these newly discovered pits are located in impact melt deposits, though five of the new pits are found in mare materials outside of impact melt deposits. Additionally, two pits are located in non-impact melt highland materials.

In a geologic context, the terms "pit" and "pit crater" have precise and varying genetic connotations (Carr and Greeley, 1980; Halliday 1998, 2008; Okubo and Martel, 1998; Cushing et al., 2007; Howard, 2010). For the purpose of this work we adopt the term "pit" to identify steep-walled negative relief features found in mare, impact melt, and highland deposits (same usage in Robinson et al, 2012). We interpret these pits to all have formed by collapse into subsurface voids, though the voids may have formed through different processes.

For this paper, pits are informally named based on nearby International Astronomical Union (IAU) named features. For example, impact melt pits are named after the crater that produced the impact melt deposit, with numbers indicating order of discovery (e.g.,

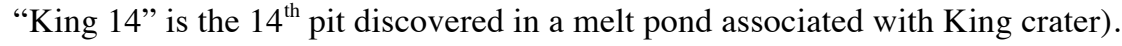

\section{Pit Morphology}

Pits, as seen in Figure 2, generally exhibit three distinct parts: the funnel, the walls, and the floor. At the top of the pit is a shallow funnel-shaped slope. There is a sharp transition to the walls, which are nearly vertical, and another sharp transition to the floor, which, when the shape can be determined, is usually flat or concave. Inner pit depth-to-diameter ratios are usually greater than 1:4 (unless otherwise noted, all diameters and depths given in this document refer to the inner pit, rather than the outer funnel). Pit floors often exhibit boulders, generally $<2 \mathrm{~m}$ in diameter, and generally have no identifiable superposed impact craters. In many cases overhangs between the steep wall and floor are visible, and may lead to extended sublunarean voids. In five pits (Mare Ingenii, Mare Tranquillitatis, Marius Hills, Southwest Mare Fecunditatis, and King 1), lateral void spaces were imaged on at least one side by slewing the Lunar Reconnaissance Orbiter spacecraft off-nadir (Robinson et al., 2012), though the extent of the sublunarean voids remains unknown. In the Lacus Mortis pit, similar imaging revealed that the vertical walls run unbroken to the current floor level on 


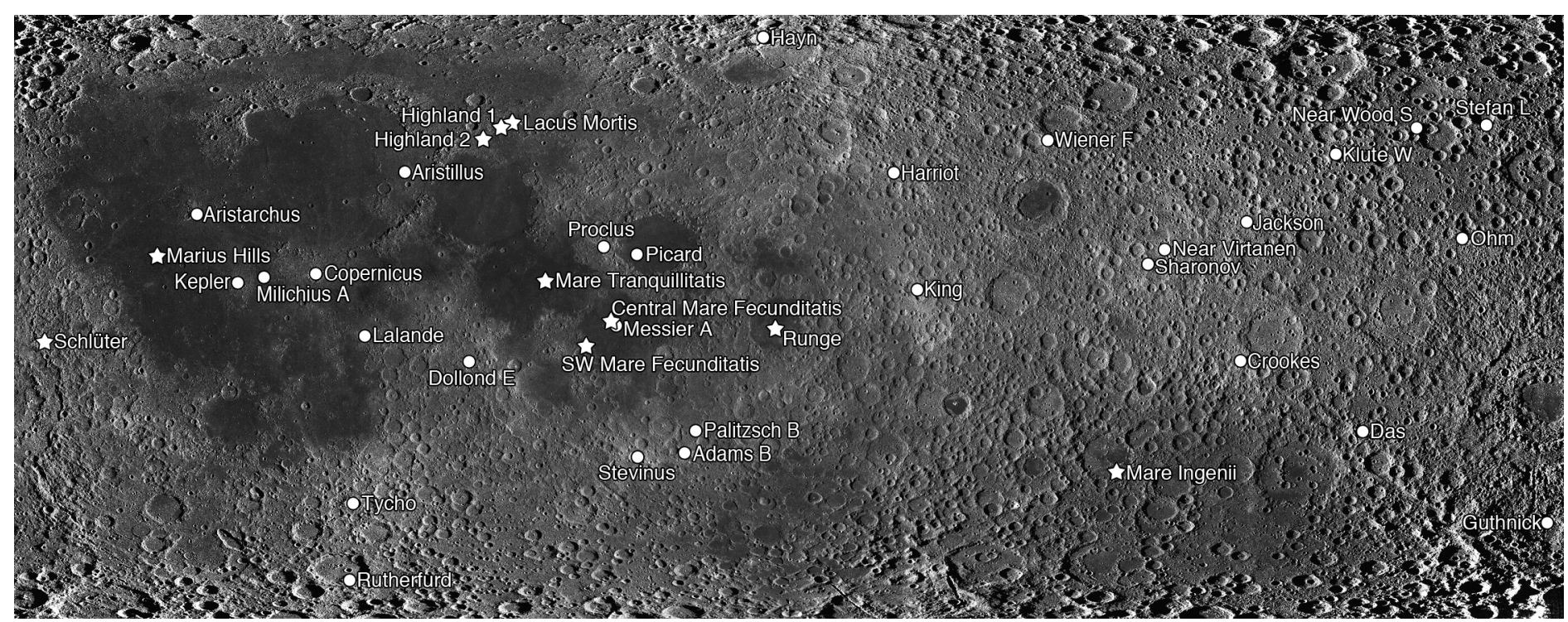

Figure 1. Map of the locations of the eight known mare pits and two known highland pits (stars), and the 29 known craters with impact melt pits (dots). Map extends from $70^{\circ} \mathrm{N}$ to $70^{\circ} \mathrm{S}, 90^{\circ} \mathrm{W}$ to $270^{\circ} \mathrm{E}$.
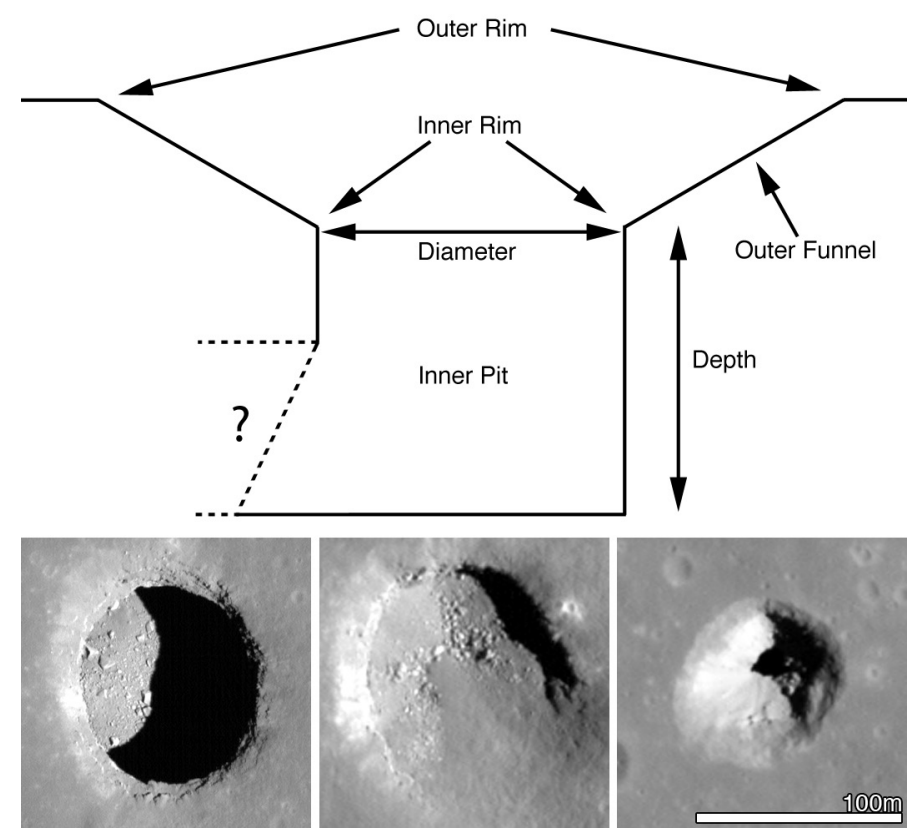

Figure 2. (Top sketch) Cross-sectional diagram of an idealized pit. Question mark and dashed lines indicate that in many cases the lower wall of a pit has not been imaged, and a void space may extend beyond the visible area. The three images at the bottom illustrate the range of relative sizes of the outer funnel and inner pit. From left to right: Mare Tranquillitatis pit (image M126710873R), Central Mare Fecunditatis pit (image M1105602888R), Southwest Mare Fecunditatis pit (image M1 105645870L). All images are at the same scale and similar Sun elevations. all sides. In a few cases, the pit wall drops down directly from the surrounding mare or melt deposit, exhibiting little to no funnel slope. This type is mostly seen in impact melt deposits, but it is also the case for the Marius Hills mare pit.

In some cases, pit floors exhibit a concave shape that contributes more to the total depth than the vertical walls do (e.g., the Central Mare Fecunditatis pit, Figure 2). This class of pit is distinguished from impact craters by the inward-facing vertical walls, lack of a raised rim, and lack of detectable ejecta. These pits also often have numerous interior blocks and few to no exterior blocks. Post-collapse debris accumulating at the base of the walls likely causes the concave-shaped floors.

Ponded impact melt deposits commonly contain fractures, which often connect to larger collapse features. These features, hereafter referred to as "fracture pits," range in morphology from wide bowl-shaped pits with barely any vertical walls to flatbottomed pits with vertical walls. The widths of the latter form can be almost as narrow as the width of the host fracture. Where it is possible to measure shadows to determine the depth of the fractures, fracture pits are no more than a few meters deeper than the parent fractures. Fracture pits are not included in the count of pits in this paper due both to their high abundance and to the difficulty of determining a definitive distinction between "fracture pit" and "fracture."

Depths for most pits were measured using shadow length, which was measured from the rim of the pit to the edge of the shadow along the projection of the solar vector onto the surface. A detailed analysis of shadow depth-measurements and their possible error sources is given in Robinson (1991). For our data set, the primary source of error is from emission angles (the angle between the vector to the camera and the surface normal) that are non-zero. Because most NAC images are nadir-pointing, we do not correct for off-nadir viewing angles. Sixty-nine percent of our shadow depthmeasurements have depth errors no greater than $10 \%$, and the 

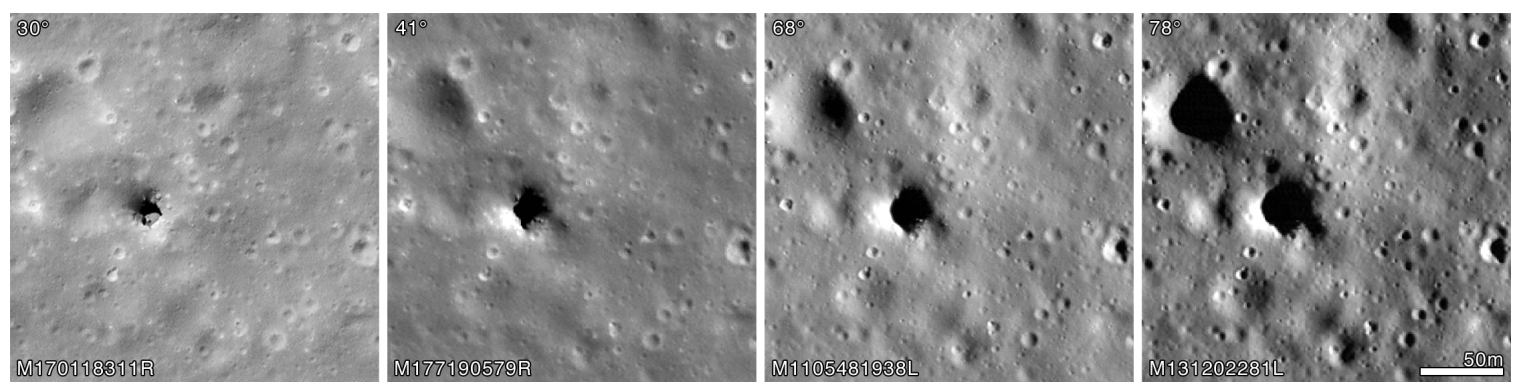

Figure 3. Four images of a pit in Palitzsch B, showing the effect of incidence angle (listed in upper-left of each frame) on pit identification.

measurements that may have errors higher than $10 \%$ only affect our statistics for the pits in Crookes and Ohm craters. For most of the mare pits, we used $2 \mathrm{~m} / \mathrm{px}$ to $5 \mathrm{~m} / \mathrm{px}$ NAC digital terrain models (Burns, 2012) to derive the depths of the funnels and inner pits, using multiple measurements to find the average rim elevation of each funnel and inner pit. The depths derived from digital terrain models were consistent with shadow measurements.

\section{Pit Search Strategy}

Since the majority of slopes on the Moon are below the angle of repose (specifically, below $36^{\circ}$ ), very few shadows are cast when the incidence angle (i.e., the angle between the solar vector and the surface normal) is less than $54^{\circ}$. Pits are an exception in that their sidewalls are typically much steeper than $36^{\circ}$ and thus can cast shadows at considerably lower incidence angles (Figure 3). We developed a program (PitScan) to search all NAC images with incidence angles less than $50^{\circ}$ to locate such shadows. Due to the incidence angle limit, only the region within $\sim 50^{\circ}$ latitude of the equator (i.e., $\sim 50^{\circ} \mathrm{S}$ to $\sim 50^{\circ} \mathrm{N}$ ) is searchable. To date, $53 \%$ of the searchable area of the Moon has been imaged within the incidence angle constraint; this has produced a total of 172,404 NAC images, and all of those images have been scanned for pits.

Because there are so many NAC images, each of which has a typical size of 5,064 samples by 52,224 lines, it is not practical to carefully search each image manually, so we developed the PitScan shadow detection algorithm to search radiometrically calibrated NAC images (16-bit integer Planetary Data System (PDS) Calibrated Data Records (CDRs), which map the 0-1 range of calibrated I/F data to a digital number (DN) range of 0-32,767) for shadows. The algorithm can complete a search of a single NAC image in thirty seconds.

PitScan first computes a cutoff threshold DN ( $T$ ) for each image, below which a pixel is treated as "shadowed." $T$ is calculated from the mean $\mathrm{DN}(\mu)$ of each image:

$$
T=\mu \times 0.113+20
$$

The threshold equation was derived from a sampling of CDRs with previously discovered pits acquired under a variety of incidence angles $\left(30^{\circ}\right.$ to $\left.60^{\circ}\right)$. The slope was calculated by applying a linear regression to the brightest pixels in each image that we considered to be in shadow, and the offset was selected so that all shadowed pixels fell below the cutoff line. Once $T$ is computed for an image, PitScan locates all blocks of contiguous shadowed pixels more than 15 pixels across and runs a DN profile in the direction of the solar azimuth for each such feature, comparing average DN values of the up-Sun and down-Sun regions of neighboring nonshadow pixels. This profile line extends approximately 30 pixels beyond the bounds of the shadow in each direction. If the ratio of the up-Sun average DN to the down-Sun average DN is greater than 9:10, the shadow is assumed to be from a positive relief feature such as a boulder and thus ignored (Figure 4). Otherwise, PitScan saves a $300 \times 300$ pixel sub-image of the shadowed area for later manual review. The 9:10 ratio was selected based on measurements from a selection of mare and impact melt pits, and it was the most restrictive ratio that did not exclude any pits.

Of the NAC images scanned, 1.7\% were feature-rich images, which means that they contained more than 50 features of interest apiece; some of them contained up to several thousand features in one image. Feature-rich images usually include large crater walls with slopes near the solar incidence angle, and all the detected features are false positives. When a feature-rich image is detected, instead of generating sub-images, PitScan creates a summary image showing the locations of all of the features detected in the image. This allows an analyst to determine if a manual search is warranted. 
Excluding the feature-rich images, the algorithm currently generates $\sim 150$ false positives for each successful pit identification. This number would be unacceptable for an algorithm designed to catalog a common feature, but since this algorithm is merely intended to assist in locating a relatively rare type of feature, the false positive rate is acceptable. The false positive rate is closely related to the ratio between the up-Sun and down-Sun average DNs used to identify boulders. $25 \%$ of false positives have ratios between 9:10 and 1:1, but only 5\% of true positives fall in that range. A minimum ratio of $11: 10$ excludes $40 \%$ of false positives, while preserving $85 \%$ of true positives. PitScan's output includes the measured brightness ratio, thereby allowing an analyst to prioritize detections that are more likely to be pits.

False positives generally fall into two categories: rocks and crater walls. Rocks that slip through the algorithmic filter, usually due to nearby slopes or shadows, are easily removed by an analyst. Sometimes crater walls are flagged because, as the slope approaches the incidence angle, small protrusions can cast large shadows without any obvious source. These shadows can be difficult to distinguish from those cast in a deep pit. An analyst can try to use surrounding features, usually texture or excessively long shadows, to identify the area as a steep slope or as a pit; if this fails, the analyst can check the original image for context. Generally, real pits are confirmed by identifying a bright down-Sun rim in the saved sub-image. Pit identifications are followed up by manually searching the full image for additional pits that, due to their small sizes, may have been missed by PitScan.

In cases where manual inspection fails to unambiguously determine whether or not a given feature is a pit, the analyst searches the NAC image library for other images that contain that location under different lighting conditions. If no other images are available, the analyst examines a larger area of the original image to see if there are any obvious features that would cause a false positive, such as the feature being on a partially-shaded crater wall.

The current version of PitScan allows an analyst to effectively check for pits in 10,000 NAC images (over 2.5 terapixels) per hour. In tests run to determine how well PitScan could identify known pits, the false negative rate for impact melt pits was around $40 \%$. This high rate of false negatives is probably due to the small size of these pits, as the median shadow length in the test images was 5
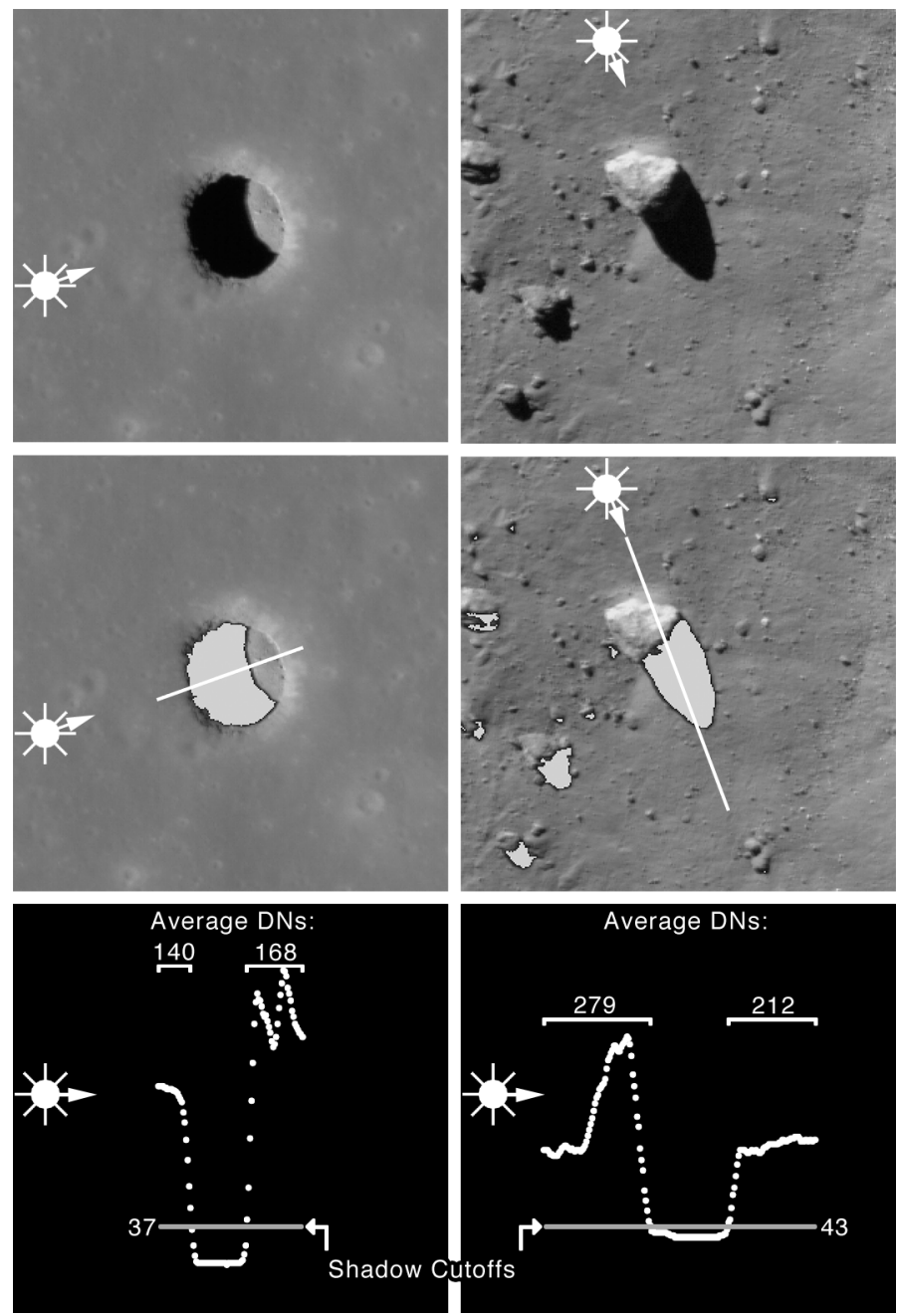

Figure 4. Annotated output frames from PitScan, comparing the DN profiles for a pit (left) and rock (right). Top panels show the area of interest; middle panels show shadowed areas and DN profile line; bottom panels show DN profile in lighting direction. Left image: M106662246R, panels are $401 \mathrm{~m}$ wide. Right image: M157412436L, panels are $148 \mathrm{~m}$ wide.

pixels. For the eight known large ( $>20 \mathrm{~m}$ diameter) mare and highland pits, there were two false negatives out of 27 images ( $7.4 \%$ ). Repeat coverage of target areas at varying lighting is essential for mitigating the number of false negatives; specifically, when an area is scanned with a range of illumination angles, it becomes easier to find a particular pit.

In addition to the automated search, several Copernican craters (Das, Faraday C, Giordano Bruno, King, Lalande, Sharonov, Tycho, and Vavilov) were manually searched for pits. These craters included both craters known to contain pits and craters, randomly selected from the Wilhelms (1987) list of Copernican craters, that did not yet have pit identifications. The manual searches of each of these craters used every available image with an incidence angle of less than $70^{\circ}$. The relaxed incidence angle constraint increased the searchable area and thereby led to the discovery of a handful of pits that were not found in images flagged by PitScan. However, unambiguous classification of features as pits was difficult without high-Sun images of the same area.

\section{Impact Melt Pits}

We have discovered 221 pits in impact melt deposits of 29 craters (summarized in Table 1). 98\% of impact melt pits are found in Copernican craters, with the exception of five pits found in two Eratosthenian craters (Klute W and Sharonov). There is no statistically significant bias towards craters with impact melt pits occurring in highland or mare terrain.

Impact melt pits are frequently irregular in outline, and their sizes range from a few meters (limited by the resolution of the images) to 


\begin{tabular}{|c|c|c|c|c|c|c|c|c|}
\hline Crater name & Lat & Lon & $\begin{array}{c}\text { Crater } \\
\text { Diameter } \\
(\mathbf{k m})\end{array}$ & $\begin{array}{c}\text { Approx. \% } \\
\text { Searched }\end{array}$ & $\begin{array}{c}\text { \# Pits }> \\
\text { 5m Wide }\end{array}$ & $\begin{array}{l}\text { Biggest Pit } \\
\text { Size }(m)\end{array}$ & $\begin{array}{c}\text { Median } \\
\text { Depth (m) }\end{array}$ & $\begin{array}{c}\text { Median } \\
\text { Diam. (m) }\end{array}$ \\
\hline King $^{\text {a }}$ & 6.5 & 119.8 & 76 & 100 & 51 & $57 \times 24 \times 13$ & 6 & 11 \\
\hline Tycho $^{b}$ & -43.3 & 348.8 & 85 & 40 & $\begin{array}{l}31 \\
35\end{array}$ & $\begin{array}{c}85 \times 60 \times 17 \\
175 \times 105 \times 32\end{array}$ & $\begin{array}{l}12 \\
13\end{array}$ & $\begin{array}{l}34 \\
38\end{array}$ \\
\hline Copernicus $^{b}$ & 9.6 & 339.9 & 96 & 75 & $\begin{array}{l}17 \\
26\end{array}$ & $\begin{array}{c}100 \times 40 \times 25 \\
900 \times 600 \times \sim 100\end{array}$ & $\begin{array}{l}11 \\
17\end{array}$ & $\begin{array}{l}14 \\
22\end{array}$ \\
\hline Lalande & -4.4 & 351.4 & 23 & 95 & 19 & $25 \times 10 \times 11$ & 5 & 10 \\
\hline Stevinus & -32.5 & 54.1 & 71 & 90 & 16 & $55 \times 30 \times 20$ & 4 & 7 \\
\hline Aristarchus & 23.7 & 312.5 & 40 & 25 & 13 & $25 \times 8 \times 14$ & 7 & 13 \\
\hline Crookes $^{c}$ & -10.4 & 194.9 & 48 & 25 & 11 & $70 \times 30 \times 17$ & 17 & 19 \\
\hline Jackson & 22.0 & 196.7 & 71 & 15 & 7 & $25 \times 14 \times 22$ & 17 & 10 \\
\hline Das & -26.6 & 223.2 & 36 & 100 & 6 & $30 \times 12 \times 14$ & 5 & 13 \\
\hline Aristillus & 33.9 & 1.2 & 54 & 20 & 4 & $28 \times 27 \times 20$ & 11 & 17 \\
\hline Kepler & 8.1 & 322.0 & 29 & 35 & 4 & $50 \times 25 \times 18$ & 8 & 11 \\
\hline Klute W & 38.0 & 216.7 & 31 & 20 & 4 & $20 \times 10 \times 8$ & 6 & 11 \\
\hline Adams B & -31.4 & 65.7 & $31 \times 25$ & 20 & 3 & $17 \times 12 \times 6$ & 5 & 11 \\
\hline Dollond E & -10.3 & 15.7 & 5 & 100 & 2 & $35 x 20 x>35$ & N/A & 24 \\
\hline Messier A & -2.0 & 46.9 & 11 & 90 & 2 & $7 \times 4 \times 6$ & 7 & 5 \\
\hline Near Wood S & 43.9 & 235.7 & 11 & 100 & 2 & $40 \times 25 \times 6$ & 7 & 19 \\
\hline $\mathrm{Ohm}^{\mathrm{c}}$ & 18.3 & 246.2 & 62 & 15 & 2 & $19 \mathrm{x} 12 \mathrm{x} \sim 18$ & 16 & 16 \\
\hline Proclus & 16.1 & 46.9 & 27 & 20 & 2 & $40 \times 25 \times 8$ & 7 & 29 \\
\hline Stefan L & 44.4 & 251.9 & 26 & 25 & 2 & $34 \times 33 \times 10$ & 10 & 28 \\
\hline Guthnick & $\begin{array}{l}-47.8 \\
\end{array}$ & 266.0 & 37 & 60 & 1 & $6 \times 5 \times 3$ & 3 & 6 \\
\hline Harriot & 33.3 & 114.4 & 38 & 15 & 1 & $30 \times 20 \times 12$ & 12 & 25 \\
\hline Hayn & 64.6 & 83.9 & 86 & 1 & 1 & $20 x 15 x \sim 6$ & 6 & 17 \\
\hline Milichius A & 9.3 & 327.9 & 8 & 100 & 1 & $13 x 10 x>17$ & N/A & 12 \\
\hline Near Virtanen & 15.8 & 177.3 & 11 & 100 & 1 & $28 \times 14 \times 17$ & 17 & 21 \\
\hline Palitzsch B & -26.3 & 68.2 & 38 & 20 & 1 & $15 \times 10 \times 10$ & 10 & 13 \\
\hline Picard & 14.6 & 54.7 & 22 & 25 & 1 & $15 \times 12 \times 6$ & 6 & 14 \\
\hline Rutherfurd & $\begin{array}{l}-61.1 \\
\end{array}$ & 347.8 & 50 & 10 & 1 & $23 \times 20 \times 4$ & 4 & 21 \\
\hline Sharonov & 12.4 & 173.1 & 75 & 60 & 1 & $5 \times 5 \times 6$ & 6 & 5 \\
\hline Wiener F & 41.2 & 150.0 & 31 & 35 & 1 & $70 \times 70 \times 20$ & 20 & 70 \\
\hline
\end{tabular}

Table 1. Craters with melt ponds that contain pits. "Approx. \% Searched" is an estimate of the percentage of the ponded impact melt that was manually searched for pits, either following up on a detection by PitScan or as part of the general search of select Copernican craters.

${ }^{a}$ Most of the King crater pits are contained in a $20 \mathrm{~km}$ diameter external melt pond in King Y crater (sometimes referred to as Al-tusi crater). The coordinates are for the center of that melt pond.

${ }^{\mathrm{b}}$ The top row gives statistics excluding bowl-shaped pits, while the bottom row includes bowl-shaped pits.

${ }^{\mathrm{c}}$ The depth measurements are uncertain due to high emission angles.

almost a kilometer across. Most impact melt pits are at the small end of that range, resulting in a median maximum diameter of $16 \mathrm{~m}$. A histogram of the maximum diameters shows exponential falloff in count as diameter increases, with successive $10 \mathrm{~m}$ bins decreasing in count by a factor of two. Impact melt pit outer funnels are rarely large enough to measure, manifesting only as a slight rounding of the rim. Due to the difficulty of distinguishing pits from impact craters at small sizes relative to the NAC resolution, pits with a maximum diameter less than $5 \mathrm{~m}$ are not included in the statistics for this study.

The largest impact melt pits have bowl-shaped floors and short walls, and they mostly occur in Copernicus and Tycho craters (see Copernicus 15, Figure 5). The largest pit of this type has a maximum diameter of $900 \mathrm{~m}$ and a maximum measured depth of $100 \mathrm{~m}$. 


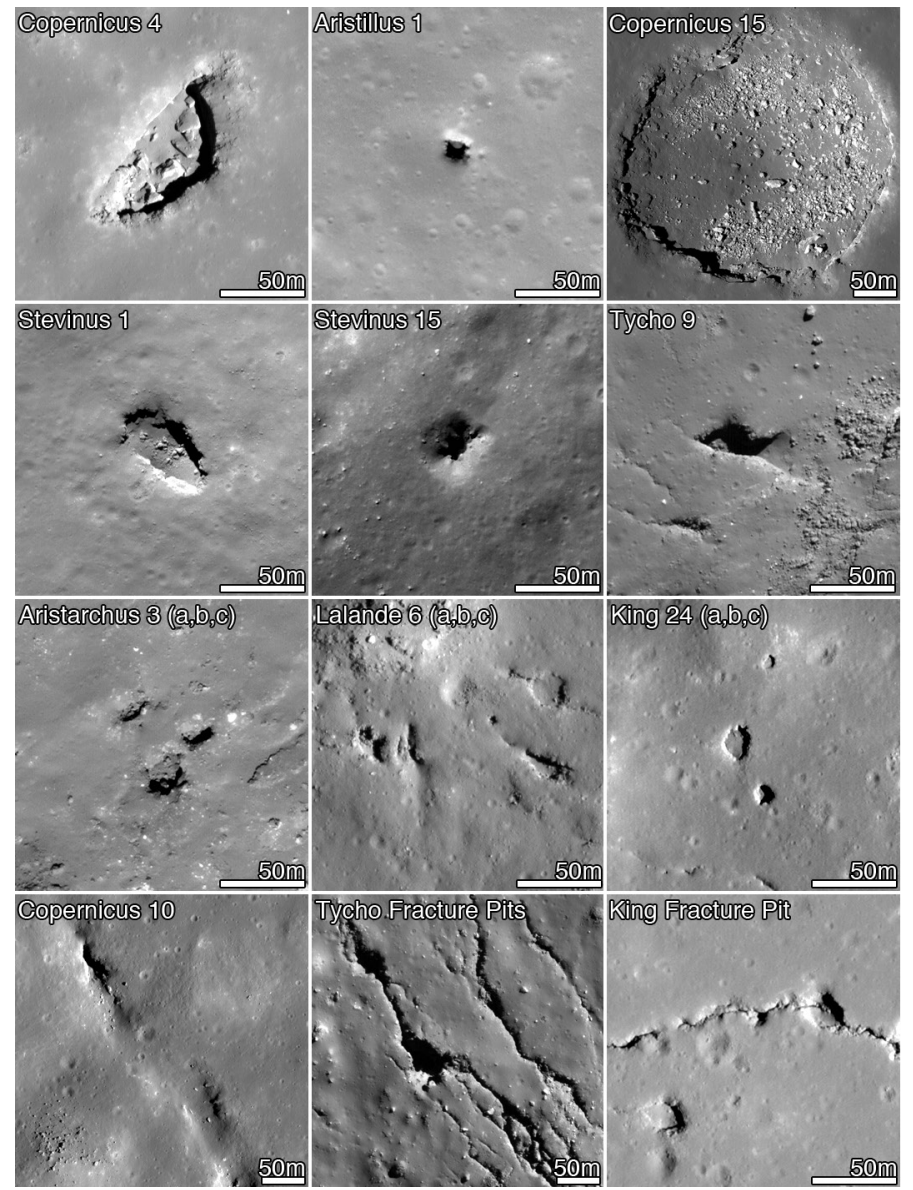

Figure 5. Examples of the morphologic variation seen in impact melt pits, fracture pits, and related features.
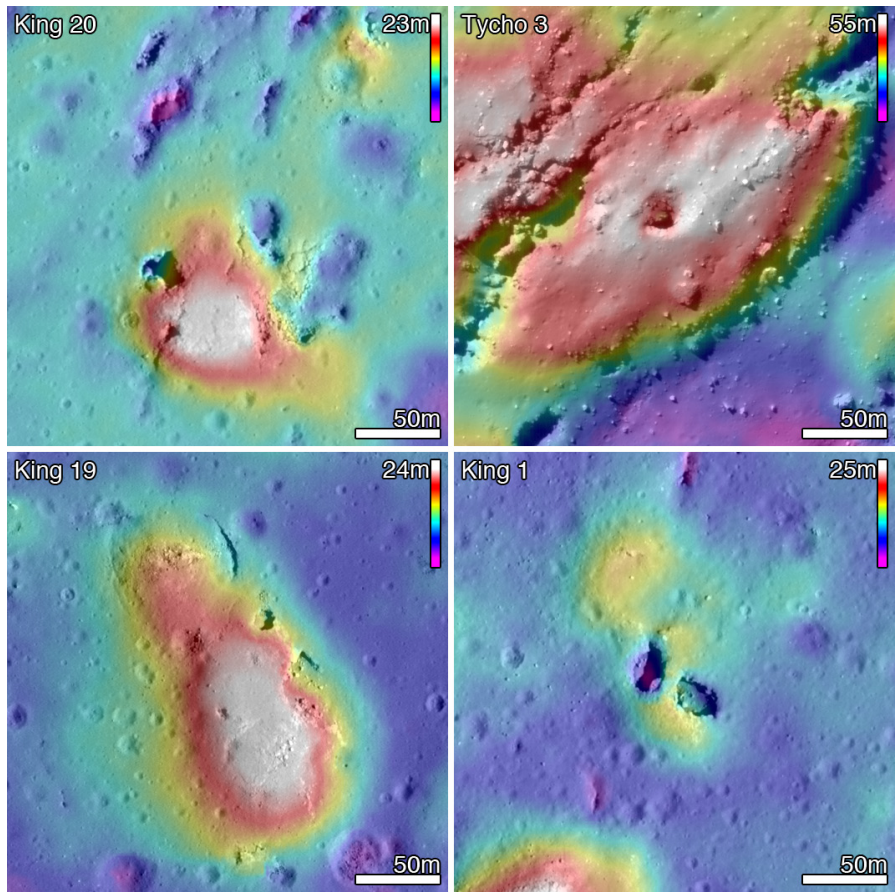

Figure 6. Pits associated with positive relief features in Tycho crater and the external King crater impact melt deposits in King $\mathrm{Y}$ crater. Color is from $2 \mathrm{~m} / \mathrm{px}$ (King) and $5 \mathrm{~m} / \mathrm{px}$ (Tycho) NAC digital elevation models, overlain on $50-\mathrm{cm} / \mathrm{px}$ NAC images. Lower-right panel shows a natural arch separating two pits, with light shining from the east, under the arch, and onto the floor of the western pit.

Measuring the depths of these pits can be difficult, because getting an accurate depth requires a solar incidence angle that places the shadow of the wall exactly in the center of the pit, so the deepest bowl-shaped pit may be more than $100 \mathrm{~m}$ deep. Of the impact melt pits with flat floors and vertical walls, the largest is $100 \mathrm{~m}$ by $40 \mathrm{~m}$ (Copernicus 4, Figure 5). The deepest non-bowl-shaped pit is approximately $30 \mathrm{~m}$ deep, and the median depth is $7 \mathrm{~m}$.

Lava tube skylights on Earth and collapse pits on other planetary bodies are frequently arranged in chains or clusters, likely corresponding to the shape of the underlying void space (Okubo and Martel, 1988; Cushing et al., 2007). Pits within impact melt deposits are only rarely found in chains or clusters when not associated with fractures. Usually, impact melt pits do not occur in organized geometric patterns within their host craters. One of the few patterns that does occur is seen in at least six craters, most notably Copernicus, where pits form within long sinuous depressions (see Copernicus 10, Figure 5). These depressions are usually about $50 \mathrm{~m}$ wide and several kilometers long, and they sometimes contain multiple pits.

The King crater impact melt pits are distinctive in several regards. First, the melt pond that contains most of the pits is located outside the crater on the King ejecta blanket in King Y crater; all other impact melt pits are found in melt pond deposits interior to the host crater. Second, the external melt pond has the highest concentration of non-fracture pits found in any melt pond to date. Third, King crater has an unusual class of pit: specifically, those formed in positive relief features (Figure 6). In one such case, two pits formed adjacent to each other in a dome over the same sub-surface void, separated by an $8 \mathrm{~m}$ wide, $5 \mathrm{~m}$ thick rock bridge (Robinson et al., 2012; Ashley et al., 2012). Slewed imaging of this feature revealed an overhang that extends at least $5 \mathrm{~m}$ south from the south end of the bridge. However, the viewing geometry is limited such that it is not possible to see underneath to the edge of the dome. The fact that void space existed under the half of the original dome that collapsed and the fact there is void space remaining beneath at least part of the remaining half of the dome show that most of the subsurface of the dome was hollow. Given that this type of pit-in-adome occurs frequently at King crater, it is possible that many of the positive relief features host voids, with their surfaces occasionally perforated with pits.

The impact melt deposit on the floor of Tycho crater exhibits a high density of fractures, fracture pits, and pits. There are numerous $>10 \mathrm{~m}$ wide linear collapses; most of these collapses have sloped walls, but some have vertical walls. Furthermore, this deposit contains both chains of pits in straight lines, which have little or no sagging in between them, and lone pits. The eastern half of 
the melt pond is generally flat with large fracture networks and scattered positive relief features. Much like in the King melt pond (Ashley et al., 2012), the fractures and linear collapses in Tycho crater generally correlate with the perimeters of kilometers-wide subtle topographic depressions. Non-fracture pits in this eastern region usually occur near the perimeter fractures rather than near the centers of the depressions. A similar distribution is seen in the King exterior melt pond, with the exception that some of the King crater pits occur in domes in the interior of topographic depressions. The western half of the melt pond is densely covered with positive relief features, containing smaller fractures than in the eastern half and no kilometer-scale depressions. Non-fracture pits in western Tycho crater primarily occur in clusters of positive relief features. Pits are evenly split between the eastern and western halves of the
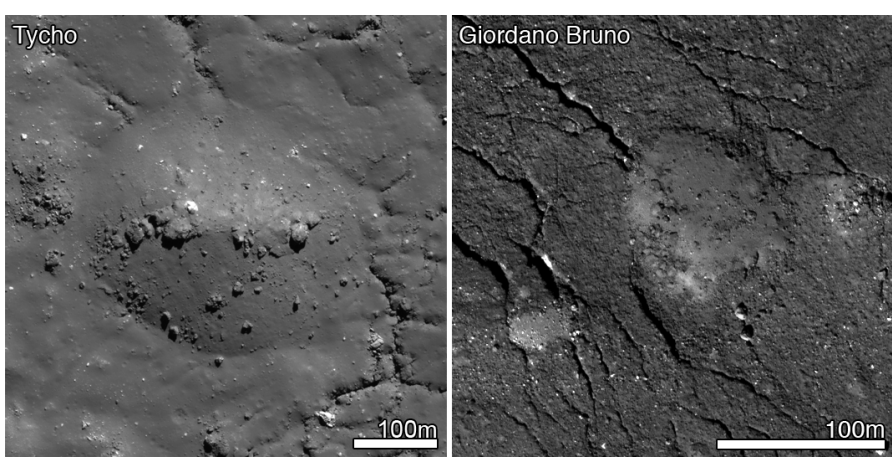

Figure 7. "Ooze domes" in Tycho and Giordano Bruno craters. crater floor, with a few pits occurring in small ponds perched on the crater walls.

One class of smooth domical features seen in Tycho and Giordano Bruno craters likely formed as melt was squeezed up (or oozed out) as pressure increased in the substrate, leading to the informal terminology "ooze domes". Ooze domes are distinctive both in their texture and in their tendency to bury underlying fractures (Figure 7).

\section{Mare Pits and Highland Pits}

In addition to the three previously known mare pits (Haruyama et al., 2009, 2010; Robinson et al., 2012), five new mare pits were discovered with PitScan (Figure 8). These eight pits are scattered across seven maria. Additionally, PitScan identified two large pits in highland terrain not associated with impact melt deposits (Figure 8).

The mare pits are all generally circular to elliptical in shape. Their outer funnels are generally more prominent than those of impact melt pits, with only three of the pits having funnels less than $10 \mathrm{~m}$ deep (Table 2). Funnel slopes of mare pits have been measured up to $45^{\circ}$; this is well above the angle of repose, indicating a solid substrate. Off-nadir images have shown layering in the walls of several mare pits (Robinson et al., 2012). In some cases (e.g., Mare Ingenii), layering is visible in the outer funnel (Figure 8).

The Marius Hills and Mare Tranquillitatis pits were both confirmed to have overhangs with void space going back more than 12 $\mathrm{m}$ and $20 \mathrm{~m}$, respectively (Robinson et al., 2012). We have since identified a void space going back at least $7 \mathrm{~m}$ in the southwest Mare Fecunditatis pit, and a void space going back at least $20 \mathrm{~m}$ under the west wall of the Ingenii pit, although there is no overhang to the east. The Lacus Mortis pit does not have overhangs on any side. The remaining mare pits either have not been imaged with appropriate geometry to identify an overhang or are too shallow for any void space to be identifiable with the resolution constraints of the NAC. It should be noted that the confirmed horizontal void depths are minimums, as no back wall has been imaged at the floor level of any of the pits with confirmed overhangs.
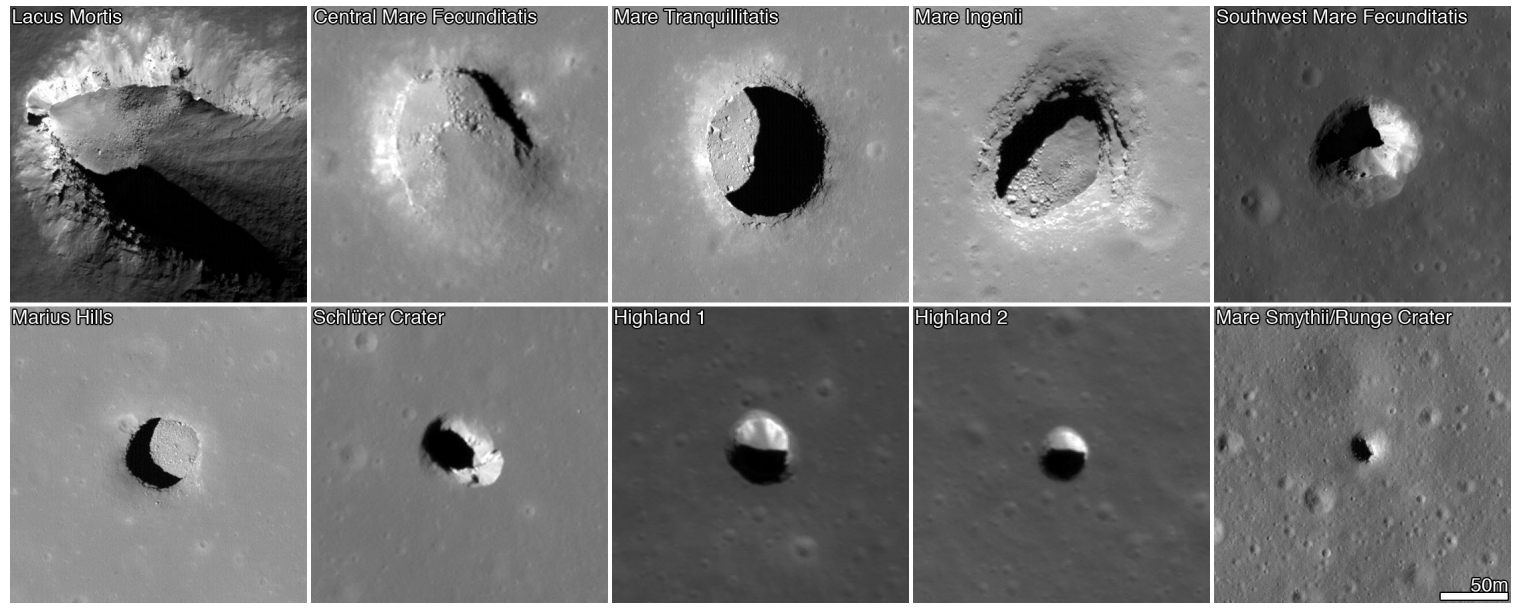

Figure 8. All of the known mare pits and highland pits (all images are 222 meters wide, locations given in Table 2). 


\begin{tabular}{|l|r|r|c|c|c|c|l|}
\hline \multirow{2}{*}{ Location } & \multirow{2}{*}{ Latitude } & \multirow{2}{*}{ Longitude } & \multicolumn{2}{|c|}{ Central Pit } & \multicolumn{2}{c|}{ Outer Funnel (approx.) } & \multirow{2}{*}{ Best Image } \\
& & & Size $(\mathrm{m})$ & Depth $(\mathrm{m})$ & Size $(\mathrm{m})$ & Depth $(\mathrm{m})$ & \multirow{2}{*}{} \\
\hline Lacus Mortis & 44.962 & 25.610 & $140 \times 110$ & 80 & $280 \times 210$ & 35 & M126759036L \\
\hline Central Mare Fecunditatis & -0.917 & 48.660 & $130 \times 110$ & $\sim 30$ & $190 \times 160$ & $\sim 15$ & M1105602888R \\
\hline Mare Tranquillitatis & 8.335 & 33.222 & $100 \times 88$ & 105 & $170 \times 150$ & $\sim 5-9$ & M126710873R \\
\hline Mare Ingenii & -35.948 & 166.053 & $100 \times 68$ & $45-65$ & $160 \times 130$ & $15-20$ & M171835900L \\
\hline Southwest Mare Fecunditatis & -6.752 & 42.759 & $16 \times 14$ & $\sim 35$ & $60 \times 55$ & $\sim 40$ & M167926438R \\
\hline Marius Hills & 14.091 & 303.230 & $58 \times 49$ & 40 & $70 \times 80$ & $\sim 4-10$ & M122584310L \\
\hline Schlüter Crater & -5.839 & 276.950 & $40 \times 20$ & $\sim 45$ & $65 \times 50$ & $\sim 15$ & M184068107L \\
\hline Highland 1 & 43.966 & 23.083 & $40 \times 40$ & $25^{\text {a }}$ & $55 \times 55$ & N/M & M185734641L \\
\hline Highland 2 & 41.156 & 18.819 & N/M & $28^{\text {a }}$ & $40 \times 35$ & N/M & M185763176L \\
\hline Runge Crater & -2.702 & 86.780 & $17 \times 13$ & 5 & N/A & N/A & M119285915R \\
\hline
\end{tabular}

Table 2. Mare and highland pits. "Best Images" correspond to the images used in Figure 8, and were chosen for maximum resolution and solar incidence and azimuth angles that enhance pit morphology.

${ }^{a}$ The central pit depth includes the depth of outer funnel.

\section{Discussion}

Pits are found in the maria $(\mathrm{n}=8)$, within impact melt deposits of Copernican and Eratosthenian craters $(\mathrm{n}=221)$, and in highland terrain $(n=2)$. Most pits discussed in this work likely result from collapse into voids formed through volcanic or tectonic processes. Previously, a class of collapse craters was identified on the Moon, on Mars, and on other terrestrial bodies in the floors of graben (Wyrick et al., 2004, Wilson et al., 2011). However, these collapse craters are generally much larger than the pits described here, and they were proposed to form from the drainage of material into void spaces formed from tectonic activity (Wyrick et al., 2004) or from large-scale volcanic intrusions (Wilson et al., 2011). One of the most prominent examples on the Moon is Rima Hyginus, a 200-kmlong graben south of Mare Vaporum that contains over twenty collapse craters. There are several theories for the formation mechanism behind this distinctive grouping of graben and craters. Fielder (1965) proposed that the graben formed as a result of strikeslip faulting and that the craters then formed by subsequent collapse into the fault. The aligned craters are most frequently thought to be collapses into volcanic voids caused by eruption or withdrawal of magma (Wilhelms, 1987). Similarly, the craters may have formed by collapse into a gas pocket that formed above magma that was intruding as a near-surface dike (Wilson et al., 2011). Because the mare pits discussed in this paper do not occur as aligned groups within graben, the formation mechanisms described above are unlikely to apply to them. Furthermore, the Lacus Mortis pit is the only one to have formed within a kilometer of a visible tectonic feature.

Only two mare pits have been found near known volcanic structures (excluding the maria themselves). The Marius Hills pit is situated inside a rille, which was likely formed by high-discharge effusive flows from the Marius Hills volcanic complex, and the Mare Tranquillitatis pit is near the center of the Cauchy shield volcano, which is proposed to cover the eastern half of Mare Tranquillitatis (Spudis et al., 2013). Four of the mare pits occur within $10 \mathrm{~km}$ of large-scale tectonic features. The Lacus Mortis pit lies adjacent to, but not within, a graben, perhaps indicating a tectonic origin. The two Mare Fecunditatis pits and the Mare Tranquillitatis pit are each located approximately $10 \mathrm{~km}$ from graben or from wrinkle ridges, too far to immediately suggest a tectonic origin. The remaining three mare pits do not have any obvious nearby volcanic or tectonic features.

The two highland pits and the Lacus Mortis pit are, along with a fourth potential collapse feature (which is difficult to distinguish from an impact crater and thus is not counted as a pit), roughly aligned along the line of the Rima Burg graben (Figure 9). The distance between any two of these three or four pits is less than the distance between any other pair of non-impact-melt pits, raising the possibility of a relationship between these pits. However, it is not clear that they are related to each other; the pits are spaced $20 \mathrm{~km}$ to $200 \mathrm{~km}$ apart, and the graben does not visibly extend beyond the bounds of Lacus Mortis. In this case, the pits may be associated with tectonic subsurface voids, but there is not sufficient evidence

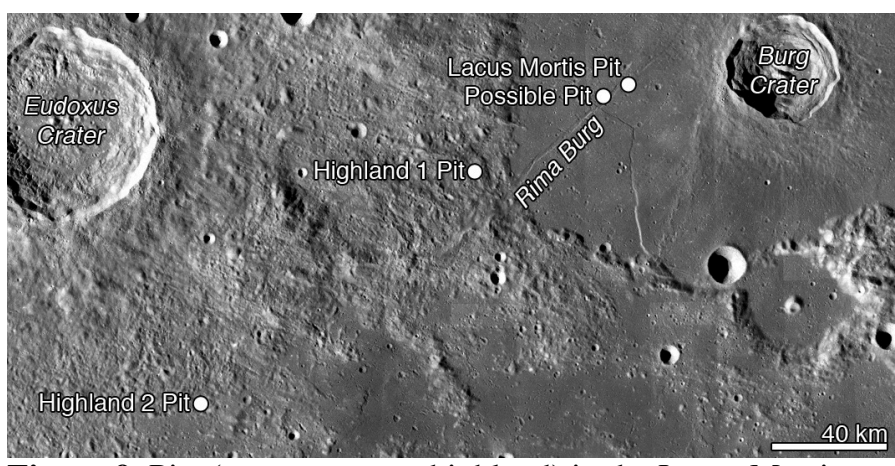

Figure 9. Pits (two mare, two highland) in the Lacus Mortis region. Image extends from $15.5^{\circ} \mathrm{E}$ to $29.9^{\circ} \mathrm{E}$, and from $40.5^{\circ}$ $\mathrm{N}$ to $45.7^{\circ} \mathrm{N}$. 
to draw a firm conclusion.

An outstanding question regards the timing of pit formation. Were the pits formed as primary features of mare emplacement or as collapses after local volcanic activity ceased?

Lava tubes on Earth result from a crust forming on a confined lava flow or from accretion of spatter along the margins of a leveed flow rather than from tunneling under the surface (Peterson and Swanson, 1974; Greeley, 1987). NAC oblique images of the three largest lunar mare pits reveal horizontally striated walls interpreted to indicate a series of lava flows up to $60 \mathrm{~m}$ thick, with individual flow thickness ranging from 3 to $14 \mathrm{~m}$ (Robinson et al., 2012). For each of these three pits, if the void space into which the pit collapsed formed as a lava tube, then based on the usual methods of lava tube formation, the flows visible above the void space must have formed later. Therefore, if the pit had formed at the same time as the void space, it would have been covered by the later flows, so the pit must have formed after all subsequent flows; it cannot be a primary skylight.

Compared to the ages of the maria, small landforms, such as the mare pits and near surface voids with a roof thickness of about $10 \mathrm{~m}$ or less, have short lifetimes. Since the maria are generally older than $2 \mathrm{Ga}$ (Wilhelms 1987), pits that formed as primary features have been erased, which is consistent with the number and size of pits discovered within the maria. The $100 \mathrm{~m}$ diameter Mare Tranquillitatis pit and the $58 \mathrm{~m}$ diameter Marius Hills pit both formed in maria older than $3.3 \mathrm{Ga}$, a surface age with a crater equilibrium diameter (Gault, 1970) of $290 \mathrm{~m}$ (Hiesinger et al., 2012). We propose that the mare pits could not have survived in their current state of preservation if they are primary features of mare emplacement. Therefore, the mare pits were almost certainly formed when the area above subsurface voids collapsed at some point after the maria were emplaced. These collapses may have been triggered by impacts (Oberbeck et al., 1969; Martellato, 2013), by single or cumulative seismic events, or by a combination thereof. Because the mare pits did not form in active lava tubes, they are not strictly speaking skylights, but rather collapse pits.

The conclusion that mare pits formed long after local magmatic activity ceased raises the question of what happened to the roof material that collapsed to form any such pit, as it could not have been carried away by flow in an active lava tube. The most likely explanation is that the collapsed material is still present in the pit. Okubo and Martel (1998) observed that terrestrial pit craters tend to get shallower and wider over time through wall collapse, and the same mechanism likely applies here. The lack of visible large blocks, which would correspond to large sections of collapsed roof, on the floors of most pits may be due to break-up of those blocks on impact with the floor, or it may simply be due to burial by the fine-grained surface regolith that would have been the last material to fall into the new pit, both in the initial collapse and from later nearby impacts. It should be noted that some pits do exhibit such large blocks on their floors (e.g., Copernicus 4; Figure 5), possibly indicating more coherent overlying rock or a thinner regolith layer.

The funnel surrounding most pits may be an indicator of the regolith depth or of the depth to which the underlying rock is heavily fractured. Layering is observed in the funnels of some mare pits (e.g., the Mare Ingenii pit; Figure 8), indicating that the funnels can extend into coherent material. Larger funnels might also correspond to older pits because, over time, meteorite impacts may expand the funnel by eroding the rim faster than the walls.

Impact melt pits are typically smaller than mare pits; all but two of the identified mare pits are over $40 \mathrm{~m}$ in diameter, while the median impact melt pit diameter is $15 \mathrm{~m}$, and only $21 \%$ of known impact melt pits have diameters greater than $40 \mathrm{~m}$. Since the diameter of a collapse pit is limited by the horizontal extent of the void into which it collapses, the fact that impact melt pits are smaller than mare pits indicates that the voids developed in impact melts are significantly smaller than those formed in maria. This difference in void sizes is likely the result of the fact that, compared to subsurface melt movement in impact melt deposits, melt moved by mare eruptive events moves at higher velocities and in larger volumes with longer durations.

We interpret that impact melt voids likely formed as melt flowed beneath a hardened crust relatively soon after parent crater formation. A large volume of impact melt, such as a kilometers-wide pond, can take tens of thousands of years to cool (Melosh, 1989). While it cools, several processes work to modify the landscape in which the melt rests, including isostatic adjustment, slumping of walls (Melosh, 1989; Bray, 2010), and subsequent primary and secondary impact events. With these dynamic forces at work, it is not surprising that subsurface movement of impact melt occurred within a cooling pond, leaving behind voids.

Pits in impact melt deposits may form in the same time period as void formation, or they may form much later, perhaps initiated when an impact event triggers a collapse. For many craters with pits, the latter scenario is the more likely of the two. This is because the surface reaches cratering equilibrium for $20 \mathrm{~m}$ diameter craters in 220 million years (Hiesinger et al., 2012), and thus any $20 \mathrm{~m}$ pits (roughly the median pit diameter) should certainly have been pulverized into oblivion by impacts within twice that time, $\sim 500$ million years. King and Copernicus craters, both about a billion years old (EI Baz 1972; Ashley et al., 2012; Hiesinger et al., 2012), have numerous $20 \mathrm{~m}$ pits. In both of these craters, the measured crater equilibrium diameter is much larger than $20 \mathrm{~m}$. Superposed

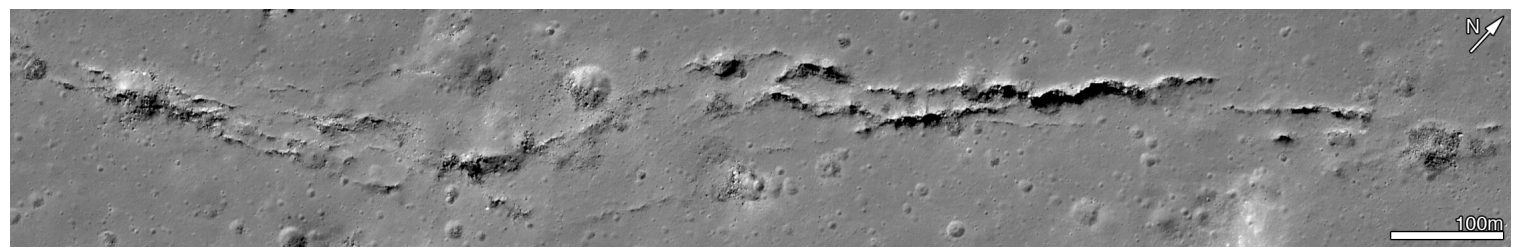

Figure 10. Fracture system in the King crater impact melt deposit in King $\mathrm{Y}$ crater. The widest fracture is $10 \mathrm{~m}$ across. 
craters on the King melt sheet are in equilibrium at a diameter in the range of $40 \mathrm{~m}$ to $50 \mathrm{~m}$ (Ashley et al., 2012), and superposed craters on the floor of Copernicus are in equilibrium at a diameter in the range of $30 \mathrm{~m}$ to $40 \mathrm{~m}$ (Hiesinger et al., 2012). The observation that morphologically crisp $20 \mathrm{~m}$ diameter pits occur in abundance at both King and Copernicus craters, and that $10 \mathrm{~m}$ wide fractures occur in abundance at King crater (Figure 7, Figure 10), demands that these small features formed well after the crater formed and the impact melt solidified.

Sublunarean voids offer both a ready-made shelter for future explorers (Hörz, 1985) and unique scientific opportunities (Robinson et al., 2012; Martellato et al., 2013). Because the fractures and pits found in impact melts are smaller and more frequently occurring than mare pits, they are likely to be more easily accessible than mare pits and thus preferable for exploration. Exploring Copernican-aged craters would allow us to observe nearly pristine examples of crater forms and to collect samples to constrain the lunar time scale for ages less than $3.2 \mathrm{Ga}$; accordingly, they are likely targets for future exploration. It is therefore serendipitous that many of these high-priority targets have abundant pits. Some pits, such as King 1 and Tycho 3 (Figure 7), may be easy enough to access that astronauts would not need ropes or other such mechanical assistance to enter them, and those pits may offer entrance to extensive sublunarean voids, which could be useful as emergency shelter. Sublunarean voids not only provide shelter from meteorite and radiation hazards but also present a relatively benign and constant thermal environment (253 K; Hörz, 1985), thereby offering yet another incentive for future exploration and exploitation.

\section{Summary and Conclusions}

A semi-automated search technique applied to LROC NAC images enabled the discovery of over 200 pits in the maria and highlands with diameters typically less than $40 \mathrm{~m}$. These pits are interpreted as having formed by collapse into voids. From the state of preservation and the age of the host materials we interpret that most pits formed as secondary features.

Pits are now relatively rare in the maria $(n=8)$, which is likely due to the ancient age of the maria. Any pit that formed as a skylight along with the maria is unlikely to have survived the subsequent billions of years of impact bombardment. Extant mare pits formed as geologically recent breaches in long-buried void spaces rather than as active skylights. Whatever the timing or the mechanism of their formation, the mare pits indicate openings to sublunarean voids.

Pits are common in impact melts of Copernican-aged craters that are at least $10 \mathrm{~km}$ in diameter. The existence of pits, fracture pits, and fractures constitute a body of evidence indicating that impact melt deposits develop internal plumbing systems. Much like mare pits, any extant pits must have formed from material collapsing into voids relatively long after their host craters formed, as older pits would have been erased over time by meteorite bombardment.

Pits offer potential access to sublunarean voids. Impact melt pits, particularly those with smooth slopes running from the rim to the floor level, are typically more accessible than mare pits, making them an attractive destination. Sublunarean voids accessible by pits would provide benign thermal conditions, shelter from meteorites, and shelter from radiation, and they would allow for easy access to material that is largely unaltered by surface processes (Taylor and Spudis, 1990; Coombs and Hawke, 1992; Robinson et al., 2012); accordingly, they are an important target for future surface exploration.

\section{Acknowledgements}

We thank Zachary Davis for proofreading the manuscript. We thank Paul Spudis and Harald Hiesinger for their helpful reviews. The NASA Lunar Reconnaissance Orbiter project funded this work. We thank the LRO Mission Operations Center personnel and the LROC Science Operations Center personnel for acquiring the data used in this study.

\section{References}

Ashley, J.W., M.S. Robinson, B.R. Hawke, C.H. van der Bogert, H. Hiesinger, H. Sato, E.J. Speyerer, A.C. Enns, R.V. Wagner, K.E. Young, and K.N. Burns, 2012. Geology of the King crater region: New insights into impact melt dynamics on the Moon, Journal of Geophysical Research, 117 http://dx .doi.org/10.1029/2011JE003990.

Bray, V. J., L. L. Tornabene, L. P. Keszthelyi, A. S. McEwen, B. R. Hawke, T. A. Giguere, S. A. Kattenhorn, W. B. Garry, B. Rizk, C. M. Caudill, L. R. Gaddis, and C. H. van der Bogert, 2010. New insight into lunar impact melt mobility from the LRO camera, Geophys. Res. Lett., 37, L21202, http://dx.doi.org/10.1029/2010GL044666.

Burns, K. N., E. J. Speyerer, M. S. Robinson, T. Tran, M. R. Rosiek, B. A. Archinal, E. Howington-Kraus, and the LROC Science Team, 2012. Digital elevation models and derived products from LROC NAC stereo observations, Int. Arch. Photogramm. Remote Sens. Spatial Inf. Sci., XXXIX-B4, 483-488, http://dx.doi.org/10.5194/isprsarchives-XXXIX-B4-483-2012, 2012.

Carr, M. H., R. Greeley, 1980. Volcanic features of Hawaii: A basis for comparison with Mars, 211 pp., NASA, SP-403, Washington, DC. 
Coombs, C. R., and B. R. Hawke (1992), A search for intact lava tubes on the Moon: Possible lunar base habitats, in The Second Conference on Lunar Bases and Space Activities of the 21st Century, NASA Conf. Publ., NASA CP-3166, vol. 1, $219-229$.

Cushing, G. E., T. N. Titus, J. J. Wynne, P. R. Christensen, 2007. THEMIS observes possible cave skylights on Mars, Geophys. Res. Lett., 34, L17201, http://dx.doi.org/10.1029/2007G1030709.

El-Baz, F., 1972. King crater and its environs, in Apollo 16 Preliminary Science Report, NASA Spec. Publ., NASA SP-315, 29-62-29-70.

Fielder, G., 1965. Lunar Geology, 184 pp,. Lutterworth Press, London.

Gault, D.E., 1970. Saturation and equilibrium conditions for impact cratering on the lunar surface: Criteria and implications, Radio Science, 5, 273-291.

Greeley, R., 1987. The role of lava tubes in Hawaiian volcanoes, Chap. 59, in R.W. Decker, T.L. Wright, and P.H. Stauffer (editors), Volcanism in Hawaii: U.S. Geological Survey Professional Paper 1350, v. 2 1589-1602.

Halliday, W. R., 1998. "Pit craters," lava tubes, and open vertical conduits in Hawaii: A problem in terminology. Bull. Nat. Speleo. Soc., 27B(1/4), pp. 113-124.

Halliday, W. R., and J. J. Wynne, 2008. Differentiating lava tube skylights from pit craters; a study of the cave-like structures on Arsia Mons, Mars. Geological Society of America Corilleran Section and Rocky Montain Section joint meeting, 40, Abstract No. 1-2. p. 33 .

Haruyama, J., K. Hioki, K. M. Shirao, T. Morota, H. Hiesinger, C. H. van der Bogert, H. Miyamoto, A. Iwasaki, Y. Yokota, M. Ohtake, T. Matsunaga, S. Hara, S. Nakanotani, C. M. Pieters, 2009. Possible lunar lava tube skylight observed by SELENE cameras, Geophys. Res. Lett., 36, L21206, http://dx.doi.org/10.1029/2009GL0406355.

Haruyama, J., S. Hara, K. Hioki, T. Morota, Y. Yokota, M. Shirao, H. Hiesinger, C. H. van der Bogert, H. Miyamoto, A. Iwasaki, M. Ohtake, Y. Saito, T. Matsunaga, S. Nakanotani, C. M. Pieters, P. G. Lucey, 2010. New Discoveries of Lunar Holes in Mare Tranquillitatis and Mare Ingenii. $41^{\text {st }}$ Lunar and Planetary Science Conference (Abstract 1285).

Hiesinger, H., C. H. van der Bogert, J. H. Pasckert, L. Funcke, L. Giacomini, L. R. Ostrach, and M. S. Robinson, 2012. How old are young lunar craters?, Journal of Geophysical Research, 117, E00H10, http://dx.doi.org/10.1029/2011JE003935.

Hörz, F., 1985. Lava tubes: potential shelters for habitats, in: Lunar bases and space activities of the 21st century (A86-30113 13-14), Houston, TX, Lunar and Planetary Institute, pp. 405-412.

Howard, K. A., 2010. Caldera collapse: Perspectives from comparing Galápagos volcanoes, nuclear-test sinks, sandbox models, and volcanoes on Mars. in: GSA Today, Geo. Soc. of America, Boulder, CO., pp. 4-10.

Martellato, E., B.H. Foing, and J. Benkhoff, 2013. Numerical modeling of impact crater formation associated with isolated lunar skylight candidates on lava tubes, Planetary and Space Science, 86, 33-44, http://dx.doi.org/10.1016/j.pss.2013.06.010.

Melosh, H. J., 1989. Impact Cratering: A Geologic Process, Oxford Monogr. Geol. Geophys., vol. 11, 245 pp., Oxford Univ. Press, New York.

Oberbeck, V.R., W.L. Quaide, R. Greeley, 1969. On the origin of lunar sinuous rilles, Modern Geol. 1, 75-80.

Okubo, C. H., Stephen J. Martel, 1998. Pit crater formation on Kilauea volcano, Hawaii, Journal of Volcanology and Geothermal Research, Volume 86, Issues 1-4, November 1998, Pages 1-18, ISSN 0377-0273, http://dx.doi.org/10.1016/S03770273(98)00070-5.

Peterson, D. W., and D. A. Swanson, 1974. Observed formation of lava tubes during 1970-71 at Kileaua volcano, Hawaii, Stud. Speoleol. 2, 209-223.

Robinson, M. S., 1991. Some aspects of Martian topography. Master's thesis. University of Hawaii, HI.

Robinson, M. S., S. M. Brylow, M. Tschimmel, D. Humm, S. J. Lawrence, P. C. Thomas, B. W. Denevi, E. Bowman-Cisneros, J. Zerr, M. A. Ravine, M. A. Caplinger, F. T. Ghaemi, J. A. Schaffner, M. C. Malin, P. Mahanti, A. Bartels, J. Anderson, T. N. Tran, E. M. Eliason, A. S. McEwen, E. Turtle, B. L. Jolliff, H. Hiesinger, 2010. Lunar Reconnaissance Orbiter Camera (LROC) Instrument Overview, Space Science Reviews, http://dx.doi.org/10.1007/s11214-010-9634-2.

Robinson, M. S., J. W. Ashley, A. K. Boyd, R. V. Wagner, E. J. Speyerer, B. R. Hawke, H. Hiesinger, and C. H. van der Bogert, 2012. Confirmation of sublunarean voids and thin layering in mare deposits, Planetary and Space Sciences, 69, http://dx.doi.org/10.1016/j.pss.2012.05.008.

Spudis, P. D., P. J. McGovern and W. S. Kiefer, 2013. Large shield volcanoes on the Moon, J. Geophys. Res. Planets, 118, 10631081, http://dx.doi.org/10.1002/jgre.20059.

Taylor, G. J., and P. D. Spudis (Eds.) (1990), Geoscience and a lunar base: A comprehensive plan for lunar exploration, NASA Conf. Publ., NASA CP-3070.

Wilhelms, D.E., 1987. The geologic history of the Moon, U.S. Geol. Surv. Prof. Paper 1348, plates 10A-11B.

Wilson, L, B. R. Hawke, T. A. Giguere, and E. R. Petrycki, 2011. An igneous origin for Rima Hyginus and Hyginus crater on the Moon, Icarus, Volume 215, Issue 2, October 2011, Pages 584-595, ISSN 0019-1035, http://dx.doi.org/10.1016/j.icarus.2011.07.003.

Wyrick, D., D. A. Ferrill, A. P. Morris, S. L. Colton, and D. W. Sims, 2004. Distribution, morphology, and origins of martian pit crater chains, J. Geophys. Res., 109, E06005, http://dx.doi.org/10.1029/2004JE002240. 